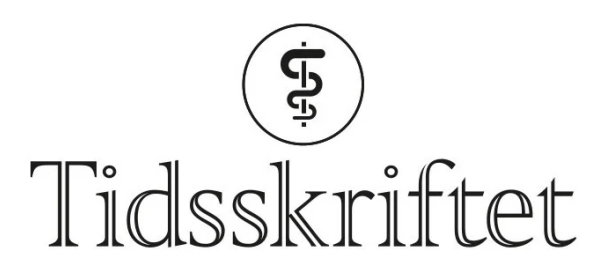

DEN NORSKE LEGEFORENING

\title{
Implantasjon av hjertestartere ved St. Olavs hospital 2006-15
}

ORIGINALARTIKKEL

\section{MATHIAS NYMAN}

fred.m.nyman@ntnu.no

Klinikk for hjertemedisin

St. Olavs hospital

og

Institutt for sirkulasjon og bildediagnostikk

Norges teknisk-naturvitenskapelige universitet

Han har bidratt med tolking av data, litteratursøk, utarbeiding/revisjon av manus og godkjenning av innsendte manusversjon.

Mathias Nyman er lege i spesialisering i indremedisin og i hjertesykdommer og stipendiat.

Forfatteren har fylt ut ICMJE-skjemaet og oppgir ingen interessekonflikter.

\section{INA CHARLOTTE MOLAUG}

Avdeling for arbeidsmedisin og epidemiologi

Statens arbeidsmiljøinstitutt

Hun har bidratt med utforming/design, innsamling, analyse og tolking av data samt litteratursøk, utarbeiding/revisjon av manus og godkjenning av innsendte manusversjon.

Ina Charlotte Molaug er lege og er stipendiat. Hun har skrevet hovedoppgave om ICD-behandling ved St. Olavs hospital.

Forfatteren har fylt ut ICMJE-skjemaet og oppgir ingen interessekonflikter.

\section{ANNE MARTE NAESS}

Avdeling for bildediagnostikk

Bærum sykehus

Hun har bidratt med utforming/design, innsamling, analyse og tolking av data samt litteratursøk, utarbeiding/revisjon av manus og godkjenning av innsendte manusversjon.

Anne Marte Næss er lege i spesialisering i radiologi. Hun har skrevet hovedoppgave om ICD-

behandling ved St. Olavs hospital.

Forfatteren har fylt ut ICMJE-skjemaet og oppgir ingen interessekonflikter.

\section{TORVALD ESPELAND}

Institutt for sirkulasjon og bildediagnostikk

Norges teknisk-naturvitenskapelige universitet

og

Klinikk for hjertemedisin

St. Olavs hospital

Han har bidratt med idé, utforming/design, innsamling, analyse og tolking av data samt litteratursøk, utarbeiding/revisjon av manus og godkjenning av innsendte manusversjon.

Torvald Espeland er spesialist i indremedisin, lege i spesialisering i hjertesykdommer og stipendiat. Forfatteren har fylt ut ICMJE-skjemaet og oppgir ingen interessekonflikter. 
Klinikk for hjertemedisin St. Olavs hospital og

Institutt for sirkulasjon og bildediagnostikk

Norges teknisk-naturvitenskapelige universitet

Han har bidratt med idé, utforming/design av studien, innsamling, analyse og tolking av data samt litteratursøk, utarbeiding/revisjon av manus og godkjenning av innsendte manusversjon.

Jan Pål Loennechen er overlege og professor.

Forfatteren har fylt ut ICMJE-skjemaet og oppgir ingen interessekonflikter.

\section{OLE CHRISTIAN MJØLSTAD}

Klinikk for hjertemedisin

St. Olavs hospital

og

Institutt for sirkulasjon og bildediagnostikk

Norges teknisk-naturvitenskapelige universitet

Han har bidratt med idé, utforming/design av studien, tolkning av data, veiledning, litteratursøk, utarbeiding/revisjon av manus og godkjenning av innsendte manusversjon.

Ole Christian Mjølstad er ph.d. og seksjonsoverlege.

Forfatteren har fylt ut ICMJE-skjemaet og oppgir ingen interessekonflikter.

\section{BAKGRUNN}

Implantasjon av hjertestarter (implantable cardioverter defibrillator, ICD) er etablert behandling hos pasienter med høy risiko for plutselig hjertedød. Studiens formål var å kartlegge pasientkarakteristika, indikasjoner, hyppigheten av ICD-støt, komplikasjoner, reoperasjoner samt endringer over tid i ICD-behandlingen ved St. Olavs hospital.

\section{MATERIALE OG METODE}

Alle pasienter som fikk implantert hjertestarter ved St. Olavs hospital i perioden 2006-15 ble inkludert. Pasientene ble identifisert i pacemakerregisteret. Data ble hentet fra pacemakerregisteret og elektronisk pasientjournal.

\section{RESULTATER}

Studien inkluderte 598 pasienter ( $82 \%$ menn, medianalder 65 år). Tidligere hjertestans eller alvorlig arytmi forelå hos 401 (67\%) av dem som fikk implantert hjertestarter.

Koronarsykdom ( $\mathrm{n}=383$ ) var vanligste underliggende årsak. I oppfølgingstiden (median 3,6 år) fikk 203 (34\%) av pasientene ICD-støt, 154 (26\%) fikk berettigede og 65 (11\%) fikk uberettigede støt. Hos 139 (23\%) pasienter oppstod komplikasjoner. 101 (17\%) pasienter døde i oppfølgingsperioden.

\section{FORTOLKNING}

Studien gir et godt grunnlag for kvalitetssikring av implantasjonsvirksomheten ved St. Olavs hospital. Kjønns- og aldersfordeling, indikasjon og underliggende årsaker for implantasjon samt hyppighet av støt og komplikasjoner samsvarer godt med tidligere publiserte data.

\section{HOVEDBUDSKAP}

Hos pasienter som fikk implantert hjertestarter (ICD) var 82 \% menn, og medianalder 65 år. Koronarsykdom var underliggende årsak til 64 \% av alle implantasjoner. $34 \%$ av pasientene opplevde støt i løpet av en median oppfølgingstid på 3,6 år. $2 \%$ fikk en infeksjon som medførte reoperasjon. 
Kardiovaskulær sykdom er den hyppigste dødsårsaken i den vestlige verden, med over 16 millioner dødsfall årlig (1, 2 ). Av disse utgjør plutselig hjerted ød en betydelig andel (3). Risikoen for plutselig d ød øker med alder og underliggende hjertesykdom og er nær tre ganger så stor hos menn som hos kvinner (4). Ventrikulær arytmi er den hyppigste arytmidiagnosen (5). Av underliggende sykdommer dominerer kardiomyopatier, kanalopatier og myokarditt blant yngre, mens det fra 30 års alder er overvekt av koronarsykdom, klaffesykdom og hjertesvikt(ㄹ).

Dødeligheten ved hjertestans er høy. Det er derfor vesentlig å identifisere pasientene med $\emptyset \mathrm{kt}$ risiko, slik at de får optimal behandling av underliggende hjertesykdom, unngår proarytmogene forhold og får behandlet kjente arytmier. Randomiserte studier har vist at implantasjon av hjertestarter (implantable cardioverter defibrillator, ICD) som primæreller sekundærprofylakse reduserer risiko for plutselig hjertedød $(\underline{6-8})$. Ramme 1 viser de mest sentrale indikasjonene for implantasjon etter gjeldende internasjonale retningslinjer, der man bør legge til grunn optimal medikamentell behandling og at pasienten vil ha over ett års forventet levetid med relativt god livskvalitet og funksjon $(\underline{2}, 9$. $)$.

\section{Ramme 1 De viktigste indikasjonene for implantasjon av hjertestarter (ICD) etter gjeldende internasjonale retningslinjer $(2,9)$.}

\section{Primærprofylaktisk indikasjon}

Alvorlig redusert venstre ventrikkel-funksjon med ejeksjonsfraksjon (LV-EF) $\leq 35 \%$ og symptomer på hjertesvikt tilsvarende New York Heart Association (NYHA)-klasse II-III (klasse IV kan aksepteres ved indikasjon for hjertetransplantasjon eller implantasjon av biventrikulær hjertestarter)

Andre tilstander med høy risiko for plutselig hjertedød som kanalopatier og særskilte kardiomyopatier med egenspesifikke kriterier

\section{Sekundærprofylaktisk indikasjon}

Overlevd hjertestans som følge av ventrikkelflimmer eller -takykardi eller hemodynamisk ustabil ventrikkeltakykardi uten påvist reversibel årsak

Uforklarlig synkope ved kjent iskemisk hjertesykdom og der invasiv elektrofysiologisk undersøkelse har indusert arytmi

Ved hjertesvikt med elektrisk dyssynkroni kan kardial resynkroniseringsterapi (CRT), et biventrikulært pacemakersystem, være indisert (10, 11). Ved høy risiko for arytmi og plutselig hjertedød kan dette systemet kombineres med en defibrillatorfunksjon (CRT-D).

ICD-behandlingen er ikke komplikasjonsfri (프). Både blødning, infeksjon, pneumothorax, tamponade eller dislokasjon av ledninger kan oppstå. Komplikasjoner kan også oppstå sent i forløpet, som infeksjon, ledningssvikt eller uberettigede støt, altså støt i fravær av ventrikulær arytmi. For mange pasienter kan det være psykisk belastende å ha hjertestarteren. Spesielt gjelder dette etter gjentatte støt, både berettigede og uberettigede (13).

Antallet ICD-implantasjoner har de senere årene økt både i Norge og Europa (14,15). Kostnad-nytte-analyser har vist at ICD-behandling basert på retningslinjer er kostnadseffektivt (므). Likevel hersker det usikkerhet omkring temaet, spesielt for pasienter $\geq 75$ år som får implantert hjertestarter (17.).

Hensikten med vår studie var å kartlegge ICD-virksomheten ved St. Olavs hospital. Vi $\emptyset$ nsket å få oversikt over pasientkarakteristika, indikasjoner, hyppighet av ICD-støt, komplikasjoner, reoperasjoner og hvordan implantasjonspraksisen har endret seg $\mathrm{i}$ tidsperioden. Resultatene ville vi sammenligne med funn i internasjonale materialer.

\section{Materiale og metode}


Alle pasienter som fikk implantert sin første hjertestarter ved St. Olavs hospital i perioden 1.1.2006-31.12.2015, ble inkludert. Pasientene ble identifisert ved søk i det lokale pacemakerregisteret NorPace, der alle pasienter som har fått satt inn eller skiftet et elektrisk implantat ved St. Olavs hospital, blir registrert. Informasjon om navn, fødselsnummer, implantasjonsdato og operasjonsindikasjon ble hentet ut.

For å sikre registreringen av komplikasjoner og å kartlegge den medisinske oppfølgingen gjennomgikk vi den elektroniske pasientjournalen (EPJ) for alle pasientene. Det ble registrert informasjon om indikasjon for implantasjon (ramme 1), underliggende hjertesykdom og relevant komorbiditet, bruk av relevante medikamenter ved utskrivning, tidlige ( $\leq$ zo dager etter implantasjon) og sene komplikasjoner, reoperasjoner, dødsdato og sluttdato for oppfølging.

Avgitte støt ble registrert. Ut ifra journalnotat ved ICD-avlesning vurderte vi om støtet var berettiget, uberettiget eller uavklart. Alle støt på samme dato ble registrert som én episode. Ved både berettigede og uberettigede støt på samme dato ble hele episoden definert som berettiget. Alle ovennevnte data ble samlet inn av to medisinstudenter og gjennomgått i samarbeid med tre erfarne leger.

Sluttdato for oppfølging ble definert som datoen da datainnsamlingen startet (20.6.2016). Dato for død, dato for fjerning/inaktivering av implantert hjertestarter eller utskrivningsdato for implantasjonsoppholdet med planlagt oppfølging på et sykehus utenfor Helse Midt-Norge, ble definert som sluttdato dersom dette inntraff før 20.6.2016. Ved flytting i løpet av oppfølgingstiden ble dato for siste ICD-kontroll i Helse Midt-Norge satt som sluttdato. Ved reoperasjon med nye ICD-komponenter ved et annet sykehus ble denne operasjonsdatoen satt som sluttdato.

Figurfremstilling, tabellutforming samt deskriptiv statistikk med beregning av gjennomsnitt, median og standardavvik ble utført med SPSS (Windows, versjon 23, IBM). Pasientdata ble avidentifisert og lagret på sikkert og tilgangsbegrenset filområde ved St. Olavs hospital. Regional etisk komité vurderte studien som en intern kvalitetssikringsstudie, og personvernombudet ved St. Olavs hospital har godkjent den etter gjeldende retningslinjer.

\section{Resultater}

Totalt 598 pasienter fikk implantert sin første hjertestarter i perioden 2006-15 ved St. Olavs hospital. Median alder for pasientene var 65 år ved implantasjon (spredning 14-84 år). Median oppfølgingstid var 3,6 år (interkvartilbredde 4,0 år, spredning o-125 måneder). I studieperioden fikk $140(23 \%)$ av pasientene en tidligere sluttdato som følge av død ( $\mathrm{n}=$ 101), tilhørighet/fraflytting til annet helseforetak $(n=23)$, hjertetransplantasjon $(n=5)$ eller andre årsaker $(\mathrm{n}=11)$.

Tabell 1 viser kliniske karakteristika for pasientene og medikamentbruk ved utskrivning etter implantasjon. 490 ( $82 \%$ av pasientene var menn. Koronarsykdom var underliggende årsak til 383 (64\%) av implantasjonene, og hos 197 (33\%) pasienter forelå primærprofylaktisk indikasjon for implantasjon (tabell 2). Fra 2006 til $2015 \emptyset k$ te årlig antall implantasjoner fra 35 til 72, mens årlig andel implantasjoner på primærprofylaktisk grunnlag økte fra $29 \%$ til $38 \%$ (figur 1).

\section{Tabell 1}

Kliniske karakteristika og medikamenter i bruk hos pasienter ved utskrivning etter førstegangs ICD-implantasjon ved St. Olavs hospital 2006-15 ( $=598$ ). Antall (\%)

Variabel Antall (\%)




\begin{tabular}{|c|c|}
\hline Variabel & Antall (\%) \\
\hline \multicolumn{2}{|l|}{ Alder ved implantasjon (år) } \\
\hline$\leq 19$ & $6(1)$ \\
\hline $20-29$ & $14(2)$ \\
\hline $30-39$ & $18(3)$ \\
\hline $40-49$ & $42(7)$ \\
\hline $50-59$ & $114(19)$ \\
\hline $60-69$ & $211(35)$ \\
\hline $70-79$ & $176(29)$ \\
\hline $80-89$ & $17(3)$ \\
\hline \multicolumn{2}{|l|}{ Kjønn } \\
\hline Menn & $490(82)$ \\
\hline Kvinner & $108(18)$ \\
\hline \multicolumn{2}{|l|}{ Komorbiditet } \\
\hline Koronarsykdom & $463(77)$ \\
\hline Atrieflimmer/atrieflutter & $207(35)$ \\
\hline Hypertensjon & $200(33)$ \\
\hline Klaffesykdom (minst grad 2 av 4 eller moderat) & $149(25)$ \\
\hline Diabetes mellitus & $112(19)$ \\
\hline Cerebrovaskulær sykdom & $94(16)$ \\
\hline Kronisk obstruktiv lungesykdom & $61(10)$ \\
\hline \multicolumn{2}{|l|}{ Medikamenter ved utskrivning } \\
\hline Betablokkere & $543(91)$ \\
\hline ACE-hemmer eller All-reseptorhemmer & $445(74)$ \\
\hline Statin eller andre lipidsenkende midler & 410 (69) \\
\hline Platehemmere & $408(68)$ \\
\hline Antikoagulantia & $224(37)$ \\
\hline Antiarytmika & $117(20)$ \\
\hline
\end{tabular}

\section{Tabell 2}

Underliggende årsak for ICD-implantasjon hos pasienter ved førstegangs implantasjon ved St. Olavs hospital 2006-15 $(\mathrm{N}=598)$. Antall (\%)

\begin{tabular}{|lccc|}
\hline Diagnose & \multicolumn{2}{c}{$\begin{array}{c}\text { Totalpopulasjon Primærprofylaktisk Sekundærprofylaktisk } \\
\text { indikasjon }\end{array}$} & \multicolumn{2}{c|}{$\begin{array}{c}\text { indikasjon } \\
{ }^{1}\end{array}$} & \\
\hline Koronarsykdom & $383(64)$ & $98(26)$ & $285(74)$ \\
\hline
\end{tabular}




\begin{tabular}{|c|c|c|c|}
\hline Diagnose & Totalpopulasjon & $\begin{array}{l}\text { Primærprofylaktisk } \\
\text { indikasjon }\end{array}$ & $\begin{array}{l}\text { Sekundærprofylaktisk } \\
\text { indikasjon }\end{array}$ \\
\hline Dilatert kardiomyopati & $103(17)$ & $69(67)$ & $34(33)$ \\
\hline $\begin{array}{l}\text { Hypertrof } \\
\text { kardiomyopati }\end{array}$ & $20(3)$ & $12(60)$ & $8(40)$ \\
\hline Annen kardiomyopati ${ }^{2}$ & $29(5)$ & $13(45)$ & $16(55)$ \\
\hline Annet $^{3}$ & $26(4)$ & $5(19)$ & $21(81)$ \\
\hline Idiopatisk sykdom & $37(6)$ & $0(0)$ & $37(100)$ \\
\hline
\end{tabular}

${ }^{1}$ Prosent regnet som andel av den aktuelle diagnosegruppen

${ }^{2}$ Manglende modning av venstre ventrikkels myokard (non-compaction kardiomyopati), alkohol-, medikament- eller pacemakerindusert kardiomyopati, arytmogen høyre ventrikkel kardiomyopati, sarkoidose eller annen avleiringssykdom, myokardaffeksjon ved eosinofil granulomatøs polyangiitt

${ }^{3}$ Klaffesykdom, myokarditt, lang QT-tid-syndrom eller annen kanalopati, medfødt hjertefeil, pulmonal hypertensjon

Totalt Primcerprofylaktisk Sekundcerprofylaktisk

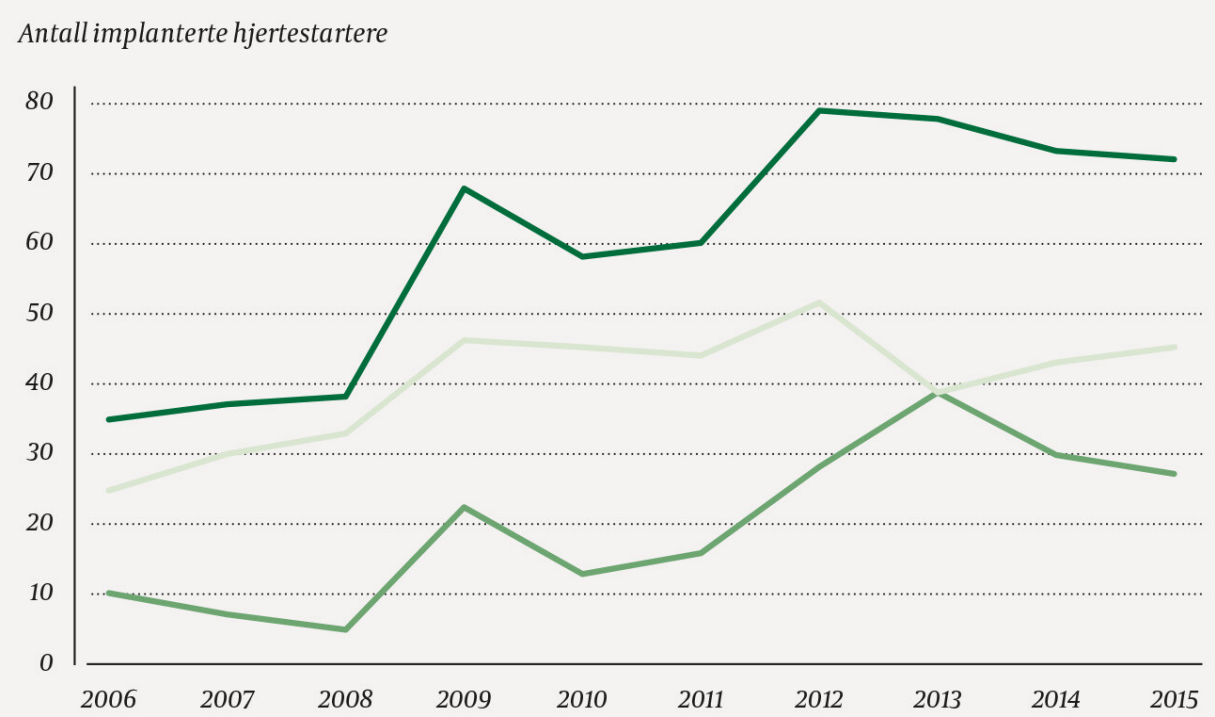

Figur 1 Totalt antall samt antall primærprofylaktiske og sekundærprofylaktiske implantasjoner av hjertestarter (ICD) ved St. Olavs hospital 2006-15 ( N = 598). Ved implantasjon av en- og tokammer-ICD var gjennomsnittlig operasjonstid $72 \pm$ 36 minutter og gjennomsnittlig stråletid per pasient $12 \pm 16$ minutter. Tilsvarende tall ved implantasjon av biventrikulær hjertestarter var henholdsvis $151 \pm 45$ minutter og $40 \pm$ 25 minutter per pasient.

Det ble registrert totalt 1034 støt (sjokk) fordelt på 409 episoder. Antall støt per episode varierte fra 1 til 47 (median 1). Av alle episodene med st $\emptyset$ t var 306/409 (75\%) berettigede, 91/409 (22 \%) uberettigede, mens 12/409 (3\%) forble uavklart.

Totalt 203/598 (34\%) av pasientene hadde støt i løpet av oppfølgingsperioden, hvorav 154/598 (26\%) opplevde berettigede og 65/598 (11\%) opplevde uberettigede støt (tabell 3 ). Det var 0,17 episoder med støt per observerte personår, hvorav 0,13 berettigede og 0,04 uberettigede episoder per personår. 


\section{Tabell 3}

Antall pasienter i utvalgte subgrupper som fikk støt i løpet av oppfølgingsperioden hos pasienter med førstegangs implantert hjertestarter (ICD) ved St. Olavs hospital 2006-15 (N =598). Antall (\% i den aktuelle subgruppen)

\begin{tabular}{|c|c|c|c|}
\hline Subgruppe & $\begin{array}{l}\text { Antall } \\
\text { pasienter }\end{array}$ & $\begin{array}{l}\text { Antall pasienter med } \\
\text { berettigede støt }(\%)\end{array}$ & $\begin{array}{l}\text { Antall pasienter med } \\
\text { uberettigede støt (\%) }\end{array}$ \\
\hline Totalt & 598 & $154(26)$ & $65(11)$ \\
\hline Menn & 490 & $127(26)$ & $55(11)$ \\
\hline Kvinner & 108 & $27(25)$ & $10(9)$ \\
\hline $\begin{array}{l}\text { ICD på primærprofylaktisk } \\
\text { indikasjon }\end{array}$ & 197 & $35(18)$ & $22(11)$ \\
\hline $\begin{array}{l}\text { ICD på } \\
\text { sekundærprofylaktisk } \\
\text { indikasjon }\end{array}$ & 401 & $119(30)$ & $43(11)$ \\
\hline Koronarsykdom & 383 & $106(28)$ & $36(9)$ \\
\hline Dilatert kardiomyopati & 103 & $25(24)$ & $13(13)$ \\
\hline
\end{tabular}

Etter førstegangs implantasjon fikk 139/598 (23\%) av pasientene én eller flere komplikasjoner av varierende alvorlighetsgrad (tabell 4). Det var ingen dødsfall relatert til selve implantasjonsprosedyren.

\section{Tabell 4}

Komplikasjoner etter implantasjon hos pasienter med førstegangs implantert hjertestarter (ICD) ved St. Olavs hospital 2006-15 $(\mathrm{N}=598)$. Totalt antall komplikasjoner (antall tidlige komplikasjoner, $\leq$ зo dager etter implantasjon)

\begin{tabular}{|lr|}
\hline Komplikasjon & Totalt antall (tidlige) \\
\hline $\begin{array}{l}\text { Reoperasjon uten infeksjon (grunnet } \\
\text { dysfungerende ledning eller generator eller revisjon } \\
\text { av lomme) }\end{array}$ & $50(8)$ \\
\hline Hematom & $45(45)$ \\
\hline Dislokasjon av ledning & $29(14)$ \\
\hline $\begin{array}{l}\text { Pneumothorax, hemothorax, perikardvæske eller } \\
\text { disseksjon av sinus coronarius }\end{array}$ & $15(15)$ \\
\hline Reoperasjon grunnet infeksjon & $12(2)$ \\
\hline Tromboemboluser & $8(4)$ \\
\hline Overflatisk sårinfeksjon & $5(1)$ \\
\hline
\end{tabular}


Det ble utført totalt 162 reoperasjoner i tidsrommet. Normal batteriutladning var hovedindikasjon for $55 / 162$ (34\%) og elektrisk ledningssvikt for $37 / 162$ (23\%) av reoperasjonene. 27 pasienter med en- eller tokammer-ICD fikk oppgradering til biventrikulær hjertestarter. Ved reoperasjon som involverte skifte av ledninger, oppsto komplikasjoner i 21/112 (18\%) av tilfellene, mens det ved reoperasjon med skifte av generator var komplikasjoner $\mathrm{i}<5$ tilfeller.

Totalt 16 ICD-anlegg hos 14 pasienter måtte ekstraheres grunnet infeksjon, tolv etter primærimplantasjon og fire etter reoperasjon.

I studieperioden fikk 40/598 (7\%) pasienter implantert ventrikkelledninger som senere ble trukket tilbake fra markedet grunnet høy hyppighet av svikt.

\section{Diskusjon}

Blant pasientene som fikk implantert sin første hjertestarter ved St. Olavs hospital i perioden 2006-15, var de fleste menn over 6o år. Koronarsykdom var vanligste tilgrunnliggende sykdom, og to tredjedeler fikk hjertestarter på sekundærprofylaktisk grunnlag. Én av tre pasienter opplevde ICD-støt i studieperioden. Livstruende komplikasjoner og infeksjoner oppsto sjelden etter implantasjon.

Kjønnsfordeling, alder og etiologi for implantasjon samsvarer med tilsvarende studier ( $\underline{18-}$ $\underline{20}$ ). Det er velkjent at koronarsykdom debuterer tidligere hos menn og at menn har høyere livstidsrisiko for plutselig hjertedød enn kvinner $(\underline{21}, \underline{22})$. Studiepopulasjonen domineres av pasienter med koronarsykdom. En tredjedel har atrieflimmer og en tredjedel har hypertensjon. Dette forklarer at en stor andel benytter platehemmende og antikoagulerende behandling og renin-angiotensin-blokade ved utskrivning etter implantasjon. Betablokkere kan forebygge ventrikulære arytmier og var som forventet svært hyppig brukt. Betablokkere er også etablert behandling av hjertesvikt og etter gjennomgått hjerteinfarkt.

I løpet av oppfølgingstiden døde $17 \%$ av pasientene. Tilsvarende tall er funnet i lignende studier $(\underline{20}, \underline{23})$. Data om dødsårsak ble ikke innhentet.

I 2015 ble 72 nye hjertestartere implantert ved St. Olavs hospital, mot 891 på landsbasis (204). Vi registrerte en betydelig $ø$ kning i antall implantasjoner i løpet av studieperioden. Andelen primærprofylaktiske implantasjoner økte betydelig og bidro følgelig til økningen i totalt antall implantasjoner.

Flere studier har vist mortalitetsreduksjon ved primærprofylaktisk ICD-implantasjon (므. 25). Dette er derfor anbefalt ved redusert venstre ventrikkel-funksjon og hjertesviktsymptomer i internasjonale retningslinjer (2).

Absolutt mortalitetsgevinst med ICD-behandling i tre år er beregnet til 5,6-9\%, mens

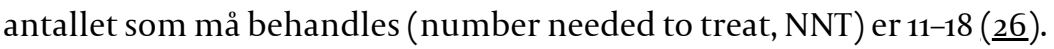

I løpet av oppfølgingstiden opplevde $26 \%$ av pasientene berettigede støt. Denne andelen var høyere i gruppen med sekundærprofylaktisk indikasjon for ICD-implantasjon. Disse pasientene, som har hatt alvorlig arytmi eller hjertestans før implantasjon, forventes å kunne få flere støt. Tilsvarende tall rapporteres i en lignende nederlandsk registerstudie med lengre median oppfølgingstid (207.).

Antall uberettigede støt per personår var avtagende jo senere ut i studieperioden hjertestarteren ble implantert (data ikke vist). Dette kan forklares av mer konservativ ICDprogrammering, med lengre deteksjonstider og $\emptyset \mathrm{kt}$ bruk av antitakykardistimulering

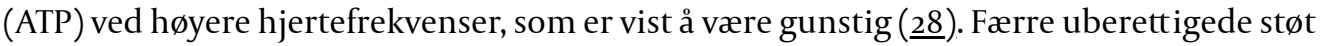
kan også skyldes tekniske fremskritt med bedre algoritmer for deteksjon av ventrikulære arytmier. 
For å redusere antallet berettigede og uberettigede støt anbefales regelmessig ICD-kontroll, fortrinnsvis med hjemmemonitorering, samt optimalisering av programmering, antiarytmisk behandling og behandling av tilgrunnliggende hjertesykdom.

Sårinfeksjon etter ICD-implantasjon er en potensielt livstruende komplikasjon og medfører ofte reoperasjon med fullstendig ekstraksjon av anlegget. I vårt materiale fikk $0,3 \%$ av pasientene tidlig infeksjon som resulterte i reoperasjon. Dette samsvarer med tall fra en tysk studie under det som benevnes som "prosedyrerelaterte komplikasjoner», men der tidsrammen for disse komplikasjonene ikke oppgis (29).). Totalt $2 \%$ av pasientene måtte reopereres grunnet infeksjon i ICD-anlegget, mens dislosert ledning etter primærimplantasjon forekom hos 4,8\%. Begge tallene samsvarer med tilsvarende studier $(\underline{2} 7$, 29).

Elektrisk ledningssvikt var blant de vanligste (23\%) indikasjonene for reoperasjon. I løpet av studieperioden ble flere ledningstyper trukket fra markedet. St. Olavs hospital fulgte retningslinjene utviklet av de respektive produsentene for profylaktisk skifte og ved påvist ledningssvikt.

Alle ICD-implantasjonene utført ved St. Olavs hospital føres fortløpende i pacemakerregisteret. Dermed er det svært sannsynlig at alle pasienter som i løpet av tiårsperioden fikk implantert ICD, er inkludert i studien. St. Olavs hospital er et stort implantasjonssenter i Norge, men relativt lite i forhold til store europeiske sentre. Sammenlignet med andre registerdata er derfor det totale antallet pasienter forholdsvis lite. En annen svakhet ved studien var at $23 \%$ av pasientene fikk en tidligere sluttdato samt at det var en kort oppfølgingstid for pasientene som fikk implantert hjertestarter i løpet av de siste årene av studien.

\section{KONKLUSJON}

Studien gir et godt grunnlag for evaluering av ICD-virksomheten ved St. Olavs hospital. Kjønns- og aldersfordeling samt underliggende sykdom som årsak for implantasjon samsvarte godt med funn fra andre studier. Årlig antall ICD-implantasjoner økte gjennom perioden. Andelen komplikasjoner samt berettigede og uberettigede støt samsvarer med resultater ved andre implantasjonssentre.

Artikkelen er fagfellevurdert.

\section{LITTERATUR}

1. Lozano R, Naghavi M, Foreman K et al. Global and regional mortality from 235 causes of death for 20 age groups in 1990 and 2010: a systematic analysis for the Global Burden of Disease Study 2010. Lancet 2012;380: 2095-128. [PubMed][CrossRef]

2. Priori SG, Blomström-Lundqvist C, Mazzanti A et al. 2015 ESC Guidelines for the management of patients with ventricular arrhythmias and the prevention of sudden cardiac death: The Task Force for the Management of Patients with Ventricular Arrhythmias and the Prevention of Sudden Cardiac Death of the European Society of Cardiology (ESC). Endorsed by: Association for European Paediatric and Congenital Cardiology (AEPC). Eur Heart J 2015; 36: 2793-867. [PubMed][CrossRef]

3. Wong CX, Brown A, Lau DH et al. Epidemiology of sudden cardiac death: Global and regional perspectives. Heart Lung Circ 2019; 28: 6-14. [PubMed][CrossRef]

4. Kannel WB, Wilson PW, D'Agostino RB et al. Sudden coronary death in women. Am Heart J 1998; 136: 205-12. [PubMed][CrossRef]

5. John RM, Tedrow UB, Koplan BA et al. Ventricular arrhythmias and sudden cardiac death. Lancet 2012; 380: 1520-9. [PubMed][CrossRef]

6. Bardy GH, Lee KL, Mark DB et al. Amiodarone or an implantable cardioverter-defibrillator for congestive heart failure. N Engl J Med 2005; 352: 225-37. [PubMed][CrossRef] 
7. Goldenberg I, Gillespie J, Moss AJ et al. Long-term benefit of primary prevention with an implantable cardioverter-defibrillator: an extended 8-year follow-up study of the Multicenter Automatic Defibrillator Implantation Trial II. Circulation 2010; 122: 1265-71. [PubMed][CrossRef]

8. Antiarrhythmics versus Implantable Defibrillators (AVID) Investigators. A comparison of antiarrhythmic-drug therapy with implantable defibrillators in patients resuscitated from near-fatal ventricular arrhythmias. N Engl J Med 1997; 337: 1576-83. [PubMed][CrossRef]

9. Al-Khatib SM, Stevenson WG, Ackerman MJ et al. 2017 AHA/ACC/HRS guideline for management of patients with ventricular arrhythmias and the prevention of sudden cardiac death. Circulation 2018; 138: e272-391. [PubMed]

10. Abraham WT, Fisher WG, Smith AL et al. Cardiac resynchronization in chronic heart failure. N Engl J Med 2002; 346:1845-53. [PubMed][CrossRef]

11. Cazeau S, Leclercq C, Lavergne T et al. Effects of multisite biventricular pacing in patients with heart failure and intraventricular conduction delay. N Engl J Med 2001;344: 873-80. [PubMed] [CrossRef]

12. Ranasinghe I, Parzynski CS, Freeman JV et al. Long-term risk for device-related complications and reoperations after implantable cardioverter-defibrillator implantation: An observational cohort study. Ann Intern Med 2016; 165: 20-9. [PubMed][CrossRef]

13. Schron EB, Exner DV, Yao Qet al. Quality of life in the antiarrhythmics versus implantable defibrillators trial: impact of therapy and influence of adverse symptoms and defibrillator shocks. Circulation 2002; 105: 589-94. [PubMed][CrossRef]

14. Steen T, Platou ES. Norsk pacemaker- og ICD-statistikk for 2017. Hjerteforum 2018; 31: 50-60.

15. Raatikainen MJ, Arnar DO, Zeppenfeld K et al. Statistics on the use of cardiac electronic devices and electrophysiological procedures in the European Society of Cardiology countries: 2014 report from the European Heart Rhythm Association. Europace 2015; 17 (suppl 1): i1-75. [PubMed][CrossRef]

16. Smith T, Jordaens L, Theuns DA et al. The cost-effectiveness of primary prophylactic implantable defibrillator therapy in patients with ischaemic or non-ischaemic heart disease: a European analysis. Eur Heart J 2013; 34: 211-9. [PubMed][CrossRef]

17. Sanders GD, Kong MH, Al-Khatib SM et al. Cost-effectiveness of implantable cardioverter defibrillators in patients >or=65 years of age. Am Heart J 2010; 160: 122-31. [PubMed][CrossRef]

18. Lin G, Meverden RA, Hodge DO et al. Age and gender trends in implantable cardioverter defibrillator utilization: a population based study. J Interv Card Electrophysiol 2008; 22: 65-70. [PubMed][CrossRef]

19. Bradshaw PJ, Stobie P, Briffa T et al. Use and long-term outcomes of implantable cardioverterdefibrillators, 1990 to 2009. Am Heart J 2013; 165: 816-22. [PubMed][CrossRef]

20. van Welsenes GH, van Rees JB, Borleffs CJ et al. Long-term follow-up of primary and secondary prevention implantable cardioverter defibrillator patients. Europace 2011; 13:389-94. [PubMed] [CrossRef]

21. Lerner DJ, Kannel WB. Patterns of coronary heart disease morbidity and mortality in the sexes: a 26-year follow-up of the Framingham population. Am Heart ] 1986; 111:383-9o. [PubMed][CrossRef]

22. Bogle BM, Ning $\mathrm{H}$, Mehrotra S et al. Lifetime risk for sudden cardiac death in the community. J Am Heart Assoc 2016; 5: eoo2398. [PubMed][CrossRef]

23. Sun S, Johnson J, Degroot P et al. Effect of ICD Therapies on Mortality in the OMNI Trial. J Cardiovasc Electrophysiol 2016; 27:192-9. [PubMed][CrossRef]

24. Platou ES, Steen T. Norsk pacemaker- og ICD-statistikk for 2015. Hjerteforum 2016; 29: 75-85.

25. Moss AJ, Zareba W, Hall WJ et al. Prophylactic implantation of a defibrillator in patients with myocardial infarction and reduced ejection fraction. N Engl J Med 2002;346: 877-83. [PubMed] [CrossRef]

26. Betts TR, Sadarmin PP, Tomlinson DR et al. Absolute risk reduction in total mortality with implantable cardioverter defibrillators: analysis of primary and secondary prevention trial data to aid risk/benefit analysis. Europace 2013; 15: 813-9. [PubMed][CrossRef]

27. van der Heijden AC, Borleffs CJ, Buiten MS et al. The clinical course of patients with implantable cardioverter-defibrillators: Extended experience on clinical outcome, device replacements, and device-related complications. Heart Rhythm 2015; 12: 1169-76. [PubMed][CrossRef]

28. Moss AJ, Schuger C, Beck CA et al. Reduction in inappropriate therapy and mortality through ICD programming. N Engl J Med 2012;367: 2275-83. [PubMed][CrossRef]

29. Alter P, Waldhans S, Plachta E et al. Complications of implantable cardioverter defibrillator therapy in 440 consecutive patients. Pacing Clin Electrophysiol 2005; 28: 926-32. [PubMed][CrossRef] 
Publisert: 28. september 2020. Tidsskr Nor Legeforen. DOI: 10.4045/tidsskr.20.0115

Mottatt 10.2.2020, første revisjon innsendt 11.5.2020, godkjent 7.7.2020.

Publisert under åpen tilgang CC BY-ND. Lastet ned fra tidsskriftet.no 26. april 2023. 